\title{
London Zoo crippled by misjudgement
}

London will lose its city-centre zoo in September if last week's flaccid announcement from the London Zoological Soclety is to be believed. This is a sad ending to a mostly honourable tale.

THE Zoological Society of London's announcement last week that its zoo in central London is to close next September is innocent of all signs of awareness of the enormity of the proposal, and of the irony that it should be closing one of the world's most accessible zoos at a time when public consciousness of the diversity of species has hardly ever been greater. It is as if the operators of a particle accelerator had decided to go out of business just when they were about to find the top quark, or some other exotic particle (see below). But there is more than black irony in what the London Zoo proposes. Through much of its history, the zoo has been managed successfully by a scientific society, whose reputation has been enhanced on that account. By the same test, the society's failure to make sense of its public responsibilities over the past five or ten years will reflect badly on its standing, as well as on the reputation for competence of other scientific societies in Britain.

In the circumstances, the comment by Lord Zuckerman on page 621 is remarkably restrained. For one who has spent a substantial part of his life's energy on the welfare of the London Zoo to see it collapse in the hands of others must be more galling than he allows. Could that collapse have been averted? The muck-raking question cannot be avoided. The Zoological Society's crucial mistake was the particular way in which it chose to use an unprecedented government grant of $£ 10$ million (in 1988) to make a dash for commercial viability. Instead of building on its own homespun strengths, and building a constituency of public support for the London Zoo, the society delegated the execution of its plans to people with an entrepreneurial cast of mind. When, just over a year ago, the money started running out, their response was to go back to the government for more against the drumbeat of a public relations campaign in which named members of endangered species were declared to be in danger individually. It was a rotten way to run a serious zoo.

But may that not have been inevitable in the closing years of Mrs Margaret (now Lady) Thatcher's era? The fashion of the times was that the crucial test of the virtue of an enterprise is its capacity to survive in the marketplace. Many British research laboratories were closed because they could not satisfy the test. (Some of those that could were promptly sold to private owners.) The trouble at the London Zoo is that it has priced itself out of the market; its admission prices are so high that its mass audience (especially among children) has been frozen out, but even the resulting revenue stream has not kept pace with mounting costs. If the London Zoo, instead of bending its energies to the sale of expensive admission tickets, had done more to sell zoology as such, it might well have acquired the stream of subscription revenue (from local authorities and private persons) on which other zoos depend. The dash for viability was a marketing exercise in favour of the wrong products.

Just where the dust will settle in the next few months is anybody's guess. The Zoological Society plans that Whipsnade Zoo should continue. It also hopes that its inhouse research institutes will continue, unaffected by the collapse of its main zoo. But that betokens a certain optimism. The institutes are at present supported by grants from the Universities Funding Council, channelled through the University of London. Their research is an interesting blend of conservation topics, animal physiology and molecular taxonomy. But the closing of the London Zoo is certain to draw attention to the anomalous status of the institutes, which would be better placed under the umbrella of the research councils. It is to be hoped that that transition will be carried out in a seemly fashion.

Whether animals will finally disappear from the site of the London Zoo in Regent's Park is also, at this stage, uncertain. A scheme canvassed by private developers for replacing the zoo by a conservation exhibit should not be scorned. Whether, at this late stage, it would be possible to rescue the zoo in its present or some similar form seems much less likely: there is precious little time between now and September. But even that apparently wild hope should not be dismissed. To let decades of intellectual and financial investment in Regent's Park be thrown away because of the misjudgements of the Zoological Society will be a great misfortune.

\section{Another phoenix?}

The SSC is not dead (yet), but the US Congress may yet force a truly international effort in high-energy physics.

Has the United States turned its back on big or even adventurous science? That is the question widely prompted by the vote in the US House of Representatives last week to deny further support for the Superconducting Super Collider (SSC), except for the pittance required to close up shop. But the vote itself does not mean that the SSC is dead. Procedurally, the Senate must first decide on the administration's request for $\$ 650$ million for the financial year beginning on 1 